\title{
Effect of timolol with and without preservative on the basal tear turnover in glaucoma
}

\author{
Esmeralda V M J Kuppens, Chris A de Jong, Thorsten R Stolwijk, Rob J W de Keizer, \\ Jaap A van Best
}

\begin{abstract}
Aims-The purpose of this study was to assess whether the preservative benzalkonium chloride (BAC 0.01\%) present in timolol induced a decrease in basal tear turnover and a deterioration of precorneal tear film in patients with glaucoma and ocular hypertension using topical timolol. Methods-The basal tear turnover of 20 patients with open angle glaucoma or ocular hypertension was measured by computerised objective fluorophotometry when using topical timolol preserved with BAC and 2 weeks after changing to topical timolol containing no preservative. Evaluation of the precorneal tear film was done by measuring the break up time (BUT) before and 2 weeks after changing medication.
\end{abstract}

Results-The tear turnover of the patients before the change was $32 \%$ lower than that of healthy controls (mean tear turnover values (SD) $(\% / \mathrm{min}): 10.7(3.0)$ and 15.6 (5.4), respectively, $\mathbf{p}<0.0001)$. A mean increase of $28 \%(47 \%)$ in the individual tear turnover values was found after the change to the preservative-free timolol $(p=0 \cdot 04)$. The BUT values before the change of medication did not differ significantly from those after the change $(p=0.5)$ but both values were significantly lower than the values of healthy controls ( $p=0.009$ and $p=0.003$, respectively).

Conclusion-Preservative-free timolol solution has a favourable effect on the tear turnover of patients with glaucoma and ocular hypertension in comparison with timolol containing BAC. The integrity of the precorneal tear film persisted to be affected when using timolol without BAC. Timolol without preservative can be recommended in those patients who have keratoconjunctivitis sicca or a borderline tear production since BAC may exacerbate a dry eye state.

(Br f Ophthalmol 1995; 79: 339-342)

Leiden Univgy,

Hospital, Leiden, the

Netherlands

E V M J Kuppens

C A de Jong

T R Stolwiik

R J W de Keizer

$\mathrm{J}$ A van Best

Correspondence to:

$\mathrm{J} A$ van Best, $\mathrm{PhD}$

Department of

Ophthalmology, University

Hospital Leiden,

Rijnsburgerweg 10, 2333 AA

Leiden, the Netherlands.

Accepted for publication

16 November 1994 ('timolol+BAC'). However, side effects like superficial punctate keratopathy, corneal anaesthesia, and burning or dry eye sensations have been reported during the use of timolol+BAC. ${ }^{2}$ Additionally, benzalkonium chloride can influence the tear film stability as has been showed previously. ${ }^{3-6} \mathrm{~A}$ new product ('timolol-BAC') has been developed in order to avoid some of the side effects of timolol+BAC. Timolol-BAC is identical in all respects to timolol+BAC except that it lacks a preservative. To guarantee sterility each package consists of a hermetically sealed single dose unit.

In a previous study ${ }^{7}$ we demonstrated a $36 \%$ lower mean basal tear turnover in patients with glaucoma using timolol+BAC in comparison with that of healthy controls. The preservative BAC is suggested as a possible cause for this decrease in tear turnover. The present follow up study was initiated to verify this assumption.

In this study the tear turnover and break up time (BUT) of the precorneal tear film of patients with open angle glaucoma and ocular hypertension were evaluated when using timolol+BAC and subsequently when using timolol-BAC. In this way we expected to find out if BAC could be held responsible for a decrease in tear production and for a deterioration of tear film stability in patients with glaucoma who use timolol+BAC. The study was set up in such a way that the same patient was measured when using timolol+BAC as well as when using timolol-BAC in order to avoid the effect of interindividual spread in tear turnover values. Note that the fluorophotometric measurement of tear turnover with a computer fluorophotometer is a quantitative method for the determination of tear production $^{7}$ and is, because of its objectivity and reproducibility, suitable for unbiased outcomes of the measurements. The precorneal tear film integrity determined by the tear film BUT and the subjective acceptability of timolol+BAC and timolol-BAC were also assessed.

\section{Material and methods}

PATIENTS

All patients were recruited from the outpatient department of the Leiden University Hospital Eye Clinic (Leiden, the Netherlands). Patients were selected according to the following criteria: (1) normal aspect of all corneal layers upon slit-lamp biomicroscopic examination; (2) open angle glaucoma or ocular hypertension for at least 6 months; (3) daily instillation of two drops of $0.25 \%$ or $0.50 \%$ timolol + BAC at 12 hour intervals for at least 1 month before measurements. Excluded were patients: (1) with intraocular pressure (IOP) values above 
$30 \mathrm{~mm} \mathrm{Hg}$ when using timolol+BAC; (2) using other topical ophthalmic medication than timolol or using systemic anti-glaucoma treatment or $\beta$ blocking medication any time before fluorophotometry; (3) wearing contact lenses.

The study was approved by the medical ethics committee of the Leiden University Hospital. Informed consent was obtained from each patient after a verbal and written explanation of the procedure of the study.

\section{MEDICATION}

Timolol+BAC (Timoptol $0 \cdot 25 \%$ and $0.50 \%$; Merck, Sharp \& Dohme, Paris, France; available in USA as Timoptic, Rahway, NJ).

Timolol-BAC (Timoptol-Ocudose $0.25 \%$ and $0.50 \%$; also Merck, Sharp \& Dohme). Both solutions were identical except for the component BAC.

\section{APPARATUS}

Fluorophotometric measurements were carried out with the Fluorotron Master (Coherent Radiation Inc, Palo Alto, CA, USA) fitted with a special lens (anterior segment adapter) for detailed scanning of the anterior segment of the eye along the optical axis. ${ }^{8}$ A reduced scanning time was used in order to prevent blinking during scanning by modifying the commercial software. ${ }^{8}$

\section{FLUOROPHOTOMETRIC PROCEDURE}

The fluorophotometric measurements were performed about 5 hours after the last timolol instillation. Four fluorophotometric scans of each cornea were carried out to determine corneal autofluorescence. ${ }^{9}$ Then $1 \mu l$ of a $2 \%$ fluorescein solution was instilled into the lateral part of the lower conjunctival fornix of each eye via a microcapillary tube according to a method described previously. ${ }^{7} 10$ Hereafter, both eyes were alternately scanned every 1.5 minutes for about 30 minutes. After the fluorophotometric measurements the cornea was examined by slit-lamp biomicroscopy. The precorneal tear film integrity was determined by the tear film BUT. BUT values of patients and healthy controls were all assessed to be shorter or longer than 10 seconds. This time represents the interval from the last blink to the first dry spot in the tear film while the fluorescein stained tear film is examined by slit-lamp biomicroscopy using cobalt light. The IOP was measured with applanation tonometry.

Basal tear turnover is defined as the tear turnover at the lowest level of reflex lacrimation possible under physiological conditions (minimally stimulated tears). Assuming that the tear film fluorescence measured was proportional to the fluorescein concentration present in the tear film, the basal tear turnover was determined from the decay of fluorescence between 5 and 30 minutes after instillation of fluorescein since at that time no reflex lacrimation was present any more and the decay of fluorescein was monophasic. ${ }^{7}$ These measurement procedures were repeated 2 weeks after the patient had changed from timolol+BAC to timolol-BAC medication with an identical percentage of timolol. An interval of 2 weeks was chosen because this time is required for the 'washout' effect of timolol+BAC. ${ }^{11}$ All patients were asked by means of a standard questionnaire whether they had any complaints related to the medication and if they preferred one of the two medications.

All measurements were carried out by the same investigators and with the same equipment as in the previous study. ${ }^{7}$ The measurements were done in the same darkened room without a direct connection with the outside. Temperature and humidity were regulated and the air movement was restricted to a minimum. Also the slit-lamp biomicroscopic examination, the BUT assessment, and IOP measurements were done by the same clinician who was not aware of the outcomes of the fluorophotometric measurements.

Previous studies ${ }^{12} 13$ showed that BAC can induce an increase in the corneal epithelial permeability. An increased penetration of fluorescein in the cornea might result in an apparently lower tear turnover value since fluorescence of the tear film is measured simultaneously with the fluorescence of the cornea as a result of the limited spatial resolution of the fluorophotometer. In order to check for corneal penetration of the instilled fluorescein, the tear turnover measurements were repeated in three patients when using timolol $+\mathrm{BAC}$ to determine the amount of fluorescein in the cornea. This was done by washing the eye with eyebaths containing saline $25-30$ minutes after the instillation of fluorescein and hereafter measuring the concentration of fluorescein present in the cornea.

\section{STATISTICAL ANALYSIS}

The paired Student's $t$ test was used for statistical analysis of the tear turnover values before and after the change of medication. The normality of tear turnover value distribution was assessed in the patients by using d'Agostino's test for departure from normality. ${ }^{14}$ The values of the patients were compared with those of 27 healthy controls measured by the same investigators in a previous study ${ }^{7}$ (mean age 58 (11) years). For evaluation of the BUT values Fisher's exact test was used and a BUT value shorter than 10 seconds was considered not normal. ${ }^{15}$

\section{Results}

Twenty patients with open angle glaucoma or ocular hypertension participated in the study (mean age 60 (SD 13) years; mean duration of using timolol before first fluorophotometric measurements 3.5 years).

Basal tear turnover values of patients when using timolol+BAC versus the values when using timolol-BAC are presented in Figure 1. The tear turnover values increased significantly after the change of medication (mean 
Table 1 Basal tear turnover, intraocular pressure, and tear film break up time

\begin{tabular}{|c|c|c|c|c|}
\hline & \multirow{2}{*}{$\begin{array}{l}\text { Tear turnover } \\
\text { Mean }(S D) \\
(\% / \text { min })\end{array}$} & \multirow{2}{*}{$\begin{array}{l}\text { IOP } \\
\text { Mean }(S D) \\
(m m \mathrm{Hg})\end{array}$} & \multicolumn{2}{|c|}{$\begin{array}{l}\text { Number of subjects with } \\
\text { tear film break up time }\end{array}$} \\
\hline & & & $<10$ seconds & $>10$ seconds \\
\hline $\begin{array}{l}\text { Patients }{ }^{\star} \text { when using timolol+BAC } \\
\text { Patients }{ }^{\star} \text { when using timolol-BAC } \\
\text { Healthy controls } \dagger\end{array}$ & $\begin{array}{l}10 \cdot 7(3 \cdot 0) \\
13 \cdot 2(5 \cdot 1) \\
15 \cdot 7(5 \cdot 3)\end{array}$ & $\begin{array}{l}17 \cdot 7(2 \cdot 0) \\
18 \cdot 1(3 \cdot 0) \\
14 \cdot 7(2 \cdot 9)\end{array}$ & $\begin{array}{l}4 \\
5 \\
0\end{array}$ & $\begin{array}{l}16 \\
15 \\
27\end{array}$ \\
\hline
\end{tabular}

${ }^{\star}$ Open angle glaucoma or ocular hypertension patients. †Measure in a previous study. ${ }^{7}$

intraindividual increase $28 \%(47 \%)$, range $-34 \%$ to $141 \%$; paired Student's $t$ test $\mathrm{p}=0.04)$. Mean basal tear turnover and IOP values before and after the change from timolol $+\mathrm{BAC}$ to timolol-BAC are presented in Table 1 . The mean tear turnover value when using timolol+BAC was significantly lower than the value of healthy controls ${ }^{7}(32 \%$ decrease; Table 1; Student's $t$ test, $\mathrm{p}<0 \cdot 0001$ ). On the other hand the mean tear turnover value when using timolol-BAC did not differ significantly from that of healthy controls $(p=0 \cdot 1$; Table 1$)$. The tear turnover values were not significantly correlated with the duration of timolol $+\mathrm{BAC}$ medication $(r<-0.4$, $\mathrm{p}>0.05)$. The mean difference between the intraindividual IOP values before and after the change of medication was not significant (mean difference $0.4 \mathrm{~mm} \mathrm{Hg}(3.2) ; \mathrm{p}=0.6$ ).

The BUT values of all patients are presented in Table 1. The BUT values when using timolol+BAC did not differ significantly from those when using timolol-BAC (Fisher's exact test: $p=0.5$ ) but both BUT values were significantly lower than those of healthy controls $(p=0.009$ and $p=0.003$, respectively). None of the 20 patients showed a superficial punctate keratopathy on final slit-lamp biomicroscopic examination after the use of timolol+BAC or after the use of timolol -BAC. Ten patients complained of burning or dry eye sensations when using timolol+BAC. These complaints diminished or disappeared after changing to timolol-BAC in nine

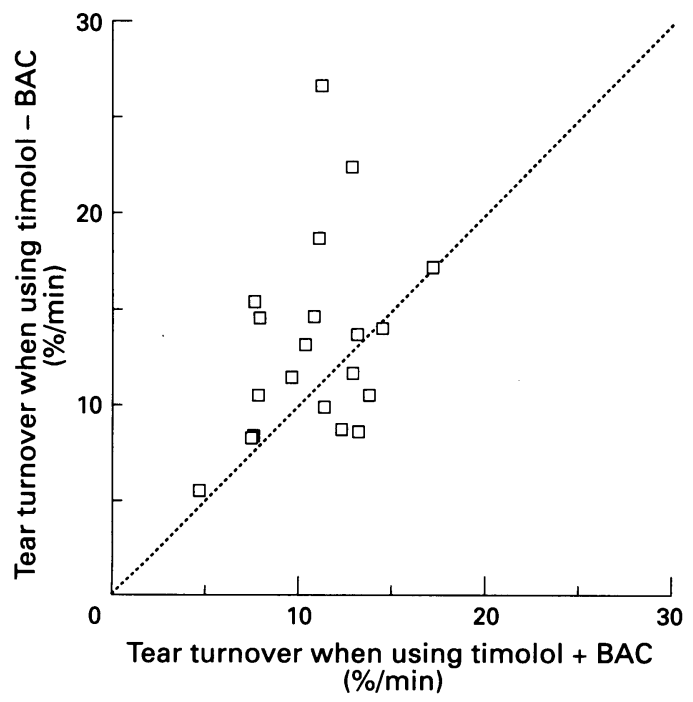

Figure 1 Basal tear turnover values expressed in per cent per minute in open angle glaucoma or ocular hypertension patients when using timolol $+B A C$ versus the values in the patients when using timolol $+B A C$ versus the values in the
same patients when using timolol-BAC for 2 weeks. The broken line represents equal values. The mean value of both eyes was used since left and right tear turnover values were correlated $(r>0.5, p<0 \cdot 05)$. patients; they all preferred using timolol -BAC. One patient preferred using timolol+BAC. The remaining 10 patients did not give any preference for either timolol $+\mathrm{BAC}$ or timolol-BAC.

Tear turnover measurements were repeated in three patients when using timolol $+\mathrm{BAC}$ in order to check for corneal penetration of fluorescein. The total fluorescein mass in the cornea amounted from $0.02 \%$ to $2.3 \%$ of that present in tear film 25-30 minutes after the fluorescein instillation. The $2 \cdot 3 \%$ value was found in a patient with evident corneal dystrophy which was confirmed by slit-lamp biomicroscopy after the measurements.

\section{Discussion}

The mean basal tear turnover values in patients with open angle glaucoma and ocular hypertension increased from 10.7 to $13.2 \% /$ minute when these patients changed from timolol $+\mathrm{BAC}$ to preservative-free timolol. This indicates an improvement of tear production towards normal values (mean tear turnover value in healthy controls is $15.6 \% /$ minute). A close inspection of Figure 1 reveals that a distinct improvement of the tear turnover $(>+10 \%)$ occurred in nine patients (average $+70 \%$ ) and a distinct deterioration of tear turnover $(<-10 \%)$ occurred in three patients (average $-28 \%$ ). Complaints about burning or dry eye sensations diminished or even disappeared in nine of the 10 patients after the change in medication. Six of them were nine patients showing a tear turnover improvement of $70 \%$ (see Figure 1). Note that the assessment of acceptability was subjective and biased since each patient knew when he was using the preservative-free timolol solution $^{16}$; this is in contrast with the fluorophotometric measurements which allowed an objective evaluation.

In a previous study ${ }^{4}$ it was demonstrated that the chronic application of timolol containing benzalkonium chloride (BAC) by glaucoma patients resulted in an impairment of the aqueous layer production rate. The increase in tear turnover values in our patients when changing from timolol $+\mathrm{BAC}$ to timolol-BAC medication corroborates these findings and demonstrates that the component BAC causes impairment of the aqueous tear flow. BAC is known to affect the superficial lipid layer of the precorneal tear film. ${ }^{17} \mathrm{~A}$ defective lipid layer results in an increased evaporation of the tear fluid. Consequently, the rate of disappearance of fluorescein will be diminished as less tear fluid is available for washing out the instilled fluorescein.

Exaggerated use of BAC can also induce epithelial damage ${ }^{12}$ and lead to an increased corneal epithelial permeability. ${ }^{13}$ Such an increased permeability can increase the corneal penetration of fluorescein and might then result in unreliable tear turnover measurements. The tear turnover values in our study are not likely to result from an increased corneal penetration of fluorescein. The mass of fluorescein in the cornea was at most $2.3 \%$ of 
that present in tear film about 25-30 minutes after instillation of fluorescein even in a patient with an evident corneal dystrophy.

The effect of BAC can be expected to occur particularly in patients using a BAC containing medication several times a day for a long period as in, for instance, dry eye syndrome and glaucoma. ${ }^{71318}$ On the other hand, it can be postulated that the effect of BAC on the basal tear turnover is presumably an immediate and reversible effect because (1) no significant correlation was found between tear turnover values and the duration of instilling BAC containing timolol in this study, and (2) removal of BAC from timolol restored the tear turnover towards normal values within 2 weeks even in glaucoma patients who have been using daily timolol+BAC for several years (mean duration of timolol $+\mathrm{BAC}$ medication in this study 3.5 years).

The BUT values of the glaucoma patients in this study did not differ significantly when changing from timolol $+\mathrm{BAC}$ to timolol-BAC medication. Note that the five patients with a decreased BUT value did not correspond to those with a decreased tear turnover value. All the patients had good eyelid hygiene and no evident pathology of their lacrimal apparatus. The reduction of the BUT could have been induced by the fluorescein used to determine the BUT since fluorescein itself can affect tear film stability. ${ }^{19}$ Yet, the BUT results of patients and healthy controls were obtained using the same method, thus making comparison possible.

The BUT values did not disagree with those in a previous study ${ }^{3}$ in which only a small increase of the values (about 2 seconds) could be found in similar patients after changing from timolol+BAC to timolol-BAC medication. Our results suggest that timolol (timolol-BAC) itself can impair the tear film stability but no direct supportive evidence is available. However, it is possible that the BUT is still impaired by BAC. BAC has been shown to affect the BUT by reducing the production of the tear film mucous layer. ${ }^{4}$ Active concentrations of BAC in the corneal epithelium and conjunctiva could be detected up to 7 days after instillation of a single drop. ${ }^{20}$ After 2 weeks of instilling timolol-BAC, it can be expected that depots of BAC are still present in the conjunctiva of glaucoma patients who have instilled multiple doses of BAC containing timolol for several years.

Timolol-BAC was found to be as effective as timolol+BAC in lowering the IOP in the patients participating in this study. Timolol-BAC can be recommended in patients who need IOP lowering and who have keratoconjunctivitis sicca or borderline tear production and in glaucoma patients who have subjective complaints about dry eye sensation when using timolol+BAC. In these cases it may be BAC that is contributing to a decreased tear production and exacerbating a dry eye state. The improved comfort of this frequently used topical drug can promote compliance with treatment for patients with glaucoma and ocular hypertension, who are often obliged to instil timolol twice a day for life.

The authors thank Chibret, MSD, for supplying timolol-BAC (Timoptol Ocudose). This study was supported in part by grants from the 'Leids Oogheelkundig Ondersteunings Fonds', Wassenaar, the Netherlands and from the 'Haags Oogheelkundig Fonds', Wassenaar, the Netherlands.

1 Van Buskirk EM. Corneal anaesthesia after timolol maleate therapy. Am F Ophthalmol 1979; 88: 739-43.

2 McMahon CD, Shaffer RN, Hoskins HD, Heteringhton J Jr. Adverse effects experienced by patients taking timolol. Am $\mathcal{F}$ Ophthalmol 1979; 88: 736-8.

3 Marquardt R, Schubert T. Beeinflussung der Tränenfilmaufreisszeit (BUT) durch Betablocker-augentropfen ohne Konservierungsstoffe. Klin Monatsbl Augenheilkd 1991; 199: 75-8.

4 Herreras JM, Pastor JC, Calonge M, Asensio VM. Ocular surface alteration after long-term treatment with an antiglaucomatous drug. Ophthalmology 1992; 99: antiglaucom

5 Strempel I. The influence of topical $\beta$-blockers on the breakup time. Ophthalmologica $1984 ; 189$ : 110-5.

6 Wilson WS, Duncan AJ, Jay JL. Effect of benzalkonium chloride on the stability of the precorneal tear film in rabbits and man. $\mathrm{Br} f$ Ophthalmol 1975; 59: 667-9.

7 Kuppens EVMJ, Stolwijk TR, de Keizer RJW, van Best JA. Basal tear turnover and topical timolol in glaucoma patients and healthy controls by fluorophotometry. Invest Ophthalmol Vis Sci 1992; 33: 3442-8.

8 De Kruijf EJFM, Boot JP, Laterveer L, van Best JA, Ramselaar JAM, Oosterhuis JA. A simple method for determination of corneal epithelial permeability in determination of corneal epithelial

9 Stolwijk TR, van Best JA, Boot JP, Oosterhuis JA. Corneal autofluorescence in diabetic and penetrating keratoplasty patients as measured by fluorophotometry. Exp Eye Res 1990; 51: 403-9.

10 Misihima S, Gasset A, Klyce Jr SD, Baum JL. Determination of tear volume and tear flow. Invest Ophthalmol Vis Sci 1966; 5: 264-76.

11 Steinert RF, Thomas JV, Boger III WP. Long-term drift and continued efficacy after multiyear timolol therapy. Arch Ophthalmol 1981; 99: 100-3.

12 Berdy GJ, Abelson MB, Smith LM, George MA. Preservative-free artificial tear preparations; assessment of corneal epithelial toxic effects. Arch Ophthalmol 1992; 110: 528-32.

13 Göbbels $M$, Spitznas $M$. Corneal epithelial permeability of dry eyes before and after treatment with artificial tears. Ophthalmology 1992; 99: 873-8.

$14 \mathrm{Zar} \mathrm{JH}$. The normal distribution. In: Kurtz B, ed. Biostatistical analysis. New Jersey: Englewood Cliffs, Prentice-Hall Inc, 1984: 79-96.

15 Lemp MA, Chacko B. Diagnosis and treatment of tear deficiencies. In: Tasman W, Jaeger EA, eds. Duane's clinical ophthalmology. Rev ed. Philadelphia: Harper \& Row, 1993; vol 4, chapter 14.

16 Vogel R. Surface toxicity of timolol [Letter]. Ophthalmology 1993; 100: 293-4.

17 Burstein NL. Basic science of ocular pharmacology. In: Bartlett JD, Jaanus SD, eds. Clinical ocular pharmacology. 2nd ed. Stoneham MA: Butterworths, 1989: 20-2.

18 Göbbels $M$, Spitznas $M$. Influence of artificial tears on corneal epithelium in dry-eye syndrome. Graefes Arch Clin Exp Ophthalmol 1989; 227: 139-41.

19 Mengher LS, Bron AJ, Tonge SR, Gilbert DJ. Effect of fluorescein instillation on the pre-corneal tear film stability. Curr Eye Res 1985; 4: 9-12.

20 Champeau EJ, Edelhauser HF. Effect of ophthalmic preservatives on the ocular surface: conjunctival and preservatives on the ocular surface: conjunctival and
corneal uptake and distribution of benzalkonium chloride corneal uptake and distribution of benzalkonium chloride
and chlorhexidine digluconate. In: Holly FJ, ed. The and chlorhexidine digluconate. In: Holly FJ, ed. The
preocular tear film. Lubbock: Dry Eye Institute, 1986: 292-302. 